\title{
Crescimento de cultivares de girassol ornamental influenciado por doses de silício no solo
}

\author{
João T. L. Oliveira', , Vinícius B. Campos², Lúcia H. G. Chaves³ \& Doroteu H. Guedes Filho ${ }^{3}$
}

RESUMO

Poucos são os trabalhos experimentais através dos quais se analisou o crescimento do girassol ornamental em condições de ambiente protegido. Objetivou-se então, no presente trabalho, avaliar doses de silicato de cálcio e magnésio no crescimento de duas cultivares de girassol ornamental. O experimento foi conduzido em casa de vegetação no período de setembro a dezembro de 2010. Os tratamentos foram dispostos no delineamento inteiramente casualizado, com três repetições, em um arranjo fatorial $5 \times 2$ referente às doses de $0 ; 2 ; 4 ; 6$ e 8 g de Si por vaso e as cultivares de girassol ornamental Jardim Amarelo Alto e Sol Vermelho. As unidades experimentais foram constituídas de vasos plásticos com capacidade de $10 \mathrm{~L}$, com $5,33 \mathrm{~L}$ de solo. Todas as unidades experimentais receberam adubação com N: $\mathrm{P}_{2} \mathrm{O}_{5}: \mathrm{K}_{2} \mathrm{O}$ nas doses de 60-80-80 $\mathrm{kg} \mathrm{ha}^{-1}$. As doses de silício aumentaram significativamente o diâmetro externo do capítulo e a abertura total do botão floral (dias) de plantas de girassol. A cultivar Sol Vermelho apresentou melhor resposta à aplicação de silício em relação ao Jardim Amarelo Alto.

Palavras-chave: Helianthus annuus L., nutrição mineral, área foliar, matéria seca

\section{Silicon fertilization on growth of ornamental sunflower cultivars}

\begin{abstract}
Few experimental studies have been carried out to analyze growth of the ornamental sunflower under protected environment conditions. Thus, the aim of this study was to evaluate effects of different silicon doses on the growth of two cultivars of ornamental sunflower. The experiment was conducted in a greenhouse, from September to December 2010. The treatments were arranged in a completely randomized design with three replications in a $5 \times 2$ factorial scheme, referring to doses $0 ; 2 ; 4 ; 6$ and $8 \mathrm{~g}$ of $\mathrm{Si}$ per pot and cultivars of ornamental sunflower Jardim Amarelo Alto and Sol Vermelho. Each experimental unit consisted of a plastic pot with a capacity of $10 \mathrm{~L}$, with $5.33 \mathrm{~L}$ of soil. All experimental units were fertilized with $\mathrm{N}: \mathrm{P}_{2} \mathrm{O}_{5}: \mathrm{K}_{2} \mathrm{O}$ in a dose of 60-80-80 kg ha-1. Doses of silicon significantly increased the external capitulum diameter and the total opening of flower bud (days) sunflower plant. The cultivar Sol Vermelho showed better response to the application of silicon compared to Jardim Amarelo Alto.
\end{abstract}

Key words: Helianthus annuus L., mineral nutrition, leaf area, dry matter

\footnotetext{
1 Secretaria de Estado do Desenvolvimento da Agropecuária e da Pesca - ULSAV Taperoá, Rua Epitássio Pessoa, s/n, CEP 58680-000, Taperoá, PB. Fone: (83) 9941-1362. E-mail: tadeuagr@hotmail.com

2 IFAP, Campus Laranjal do Jari, Rua Nilo Peçanha, 1263, Cajari, CEP 68920-000, Laranjal do Jari, AP. Fone: (96) 3621-1631. E-mail: vinicius.campos@ifap.edu.br

${ }^{3}$ UAEA/UFCG, Avenida Aprígio Veloso, 882, Bodocongó, CEP 58109-900, Campina Grande, PB. Fone: (83) 2101-1285. E-mail: Ihgarofalo@hotmail.com; doroteufilho@hotmail.com
} 


\section{INTRODUÇÃO}

O girassol (Helianthus annuus L.) está entre as cinco maiores culturas oleaginosas e responde por cerca de $13 \%$ de todo o óleo vegetal produzido no mundo (EMBRAPA, 2003). Além disto o girassol ganhou, nos últimos anos, o girassol destaque como planta ornamental na produção de flores de corte e de vaso (Schoellhorn et al., 2003).

$\mathrm{O}$ girassol ornamental pode ser cultivado em qualquer região do País, apresentando-se como alternativa para o setor da floricultura, por se tratar de uma cultura sem grandes dificuldades de manejo. A cultura tem ampla adaptabilidade climática, alta tolerância à seca, ao frio e ao calor, tornando-se pouco influenciada pela latitude, altitude e pelo fotoperíodo (Zobiole et al., 2010).

A análise de crescimento é um método que segue a dinâmica da produção fotossintética sendo de vital importância para se compreender os processos morfofisiológicos da planta e sua influência sobre o rendimento. A produção de flores e o tamanho da flor e da haste são características definidas pela potencialidade genética e podem ser influenciadas pela nutrição mineral das plantas (Higaki et al., 1992).

O silício não é considerado um nutriente essencial para os vegetais uma vez que não atende aos critérios diretos e indiretos de essencialidade; apesar disto, diversos pesquisadores (AlAghabaruy et al., 2004; Amaral et al., 2008; Pinto et al., 2009; Lima et al., 2011) têm encontrado resultados positivos avaliando o efeito da escória de siderurgia, tanto nos solos como nas plantas. As principais respostas das culturas ao silício são de maior resistência das plantas às doenças e pragas; tolerância à toxicidade por metais pesados; tolerância a estresses hídricos e salinos; menor transpiração; promoção de crescimento e nodulação em leguminosas; efeito na atividade de enzimas e na composição mineral; melhoria da arquitetura da planta, o que facilita a mecanização; redução no acamamento e consequente aumento da taxa fotossintética e de produtividade, sobretudo em cana-de-açúcar (Demattê et al., 2011). Apesar desses efeitos do silício, outros tantos surgem de forma contraditória em razão de ainda não se conhecer exatamente as funções do silício nas plantas; como ele atua na sua fisiologia; quais as plantas mais beneficiadas com sua presença e quais as doses mais adequadas para cada tipo de cultura (Rodrigues et al., 2011). Carvalho et al. (2009) avaliando em seus resultados o efeito do silício no girassol ornamental em vaso, apontam que o girassol pode ser considerado cultura acumuladora de silício e que, na presença deste elemento, ocorreu aumento na produção e na melhoria da qualidade do girassol.

Diante do exposto o objetivo deste trabalho foi avaliar o efeito de doses de silício sobre o crescimento de duas variedades de girassol ornamental cultivadas em ambiente protegido.

\section{Material e Métodos}

O experimento foi conduzido entre setembro e dezembro de 2010 em casa de vegetação pertencente à Unidade Acadêmica de Engenharia Agrícola, vinculada ao Centro de Tecnologia e Recursos Naturais (CTRN) da Universidade Federal de Campina Grande (UFCG - PB), Campina Grande, PB (coordenadas geográficas: $7^{\circ} 15^{\prime} 18^{\prime \prime}$ de latitude Sul, $35^{\circ} 52^{\prime} 40^{\prime \prime}$ longitude Oeste e altitude de $550 \mathrm{~m}$ ). Conforme a classificação climática de Köppen, adaptada ao Brasil (Coelho \& Soncin, 1982), o clima da região é do tipo Csa, que representa clima mesotérmico, subúmido, com período de estiagem quente e seco (4 a 5 meses) e período chuvoso de outono a inverno.

Os tratamentos foram constituídos de cinco doses de silício ( $0 ; 2 ; 4 ; 6$ e 8 g de silício por vaso) provenientes de escória de siderurgia contendo $25 \%$ de cálcio, $6 \%$ de magnésio e $10,5 \%$ de silício (Agrossilício plus) aplicadas nas variedades de girassol Jardim Amarelo Alto e Sol Vermelho (ISLA Sementes) para fins ornamentais. Os tratamentos foram dispostos no delineamento inteiramente casualizado, no esquema fatorial $5 \times 2$, com três repetições.

As unidades experimentais foram vasos de polietileno com capacidade para $10 \mathrm{~L}$ preenchidos com 1,0 L de brita (número zero) a qual cobria a base do vaso seguida de $5,33 \mathrm{~L}(8,0 \mathrm{~kg})$ de material de solo classificado como Neossolo Regolitico eutrófico, de textura franco-arenosa, não salino e não sódico, proveniente do município de Campina Grande, PB. Conforme os métodos recomendados pela EMBRAPA (1997) o solo foi analisado, cujos resultados da análise química foram: $\mathrm{pH}\left(\mathrm{H}_{2} \mathrm{O}\right)$ $=6,7 ; \mathrm{P}=37,32 \mathrm{mg} \mathrm{dm}^{-3} ; \mathrm{Ca}=1,85 \mathrm{cmol}_{\mathrm{c}} \mathrm{dm}^{-3} ; \mathrm{Mg}=2,25$ $\mathrm{cmol}_{\mathrm{c}} \mathrm{dm}^{-3} ; \mathrm{K}=0,37 \mathrm{cmol}_{\mathrm{c}} \mathrm{dm}^{-3} ; \mathrm{Na}=0,05 \mathrm{cmol}_{\mathrm{c}} \mathrm{dm}^{-3} ; \mathrm{B}=0,49$ $\mathrm{cmol} \mathrm{dm}^{-3} ; \mathrm{CTC}=6,12 \mathrm{cmol} \mathrm{dm}^{-3} ; \mathrm{MO}=37,1 \mathrm{~g} \mathrm{dm}^{-3} ;$ areia $=$ $827 \mathrm{~g} \mathrm{~kg}^{-1}$; silte $=99 \mathrm{~g} \mathrm{~kg}^{-1}$; argila $=74 \mathrm{~g} \mathrm{~kg}^{-1}$; densidade $=1,5$.

As doses de silício foram misturadas aos $8 \mathrm{~kg}$ de material de solo provenientes de cada tratamento e incubadas com umidade próximo de $80 \%$ da capacidade de campo durante trinta dias, para a reação do silício no solo. Após a incubação todas as unidades experimentais receberam adubação com nitrogênio (N), fósforo (P) e potássio (K) nas dosagens de $60-80-80 \mathrm{~kg} \mathrm{ha}^{-1}$. A fonte de $\mathrm{N}$ foi a uréia, com $45 \% \mathrm{~N}$; de $\mathrm{P}$ o superfostato triplo com $46 \%$ de $\mathrm{P}$ e de $\mathrm{K}$ o cloreto de potássio com $60 \%$ de K. Além disto, foram fornecidos $10,6 \mathrm{mg}$ por vaso de boro, provenientes do ácido bórico, uma vez que é essencial a aplicação de boro para o plantio de girassol.

Após a incubação 10 sementes de girassol foram semeadas equidistantes $2 \mathrm{~cm}$ de profundidade por vaso; aos 15 dias após a semeadura (DAS) efetuou-se o desbaste deixando-se apenas uma planta por vaso.

O solo foi irrigado até atingir a capacidade de campo (CC) de forma a garantir a efetivação do processo de emergência e do desenvolvimento das plantas. O manejo da água foi realizado mediante o processo de pesagem dos vasos, de modo a fornecer o volume de água evapotranspirada no intervalo de $24 \mathrm{~h}$.

Aos 60 DAS foram avaliados a altura de planta (AP) (medida na distância entre o colo da planta e a inserção do capítulo); o diâmetro caulinar (DC) (medido no colo da planta com um paquímetro); o número de folhas (contagem das folhas totalmente expandidas com comprimento mínimo de $2 \mathrm{~cm}$ ) e a área foliar (AF) (determinada conforme Maldaner et al. (2009), usando-se a seguinte equação: $\mathrm{AF}=1,7582 \mathrm{~L}^{1,7067}$, sendo o "L" a largura do limbo foliar). A fitomassa seca da parte aérea (FSPA), fitomassa seca de folhas (FSF) e fitomassa seca de inflorescência (FSI) foram avaliadas após secagem em estufa com ventilação forçada de ar a $65^{\circ} \mathrm{C}$, até a obtenção de peso constante; os diâmetros externo (DCe) e interno do capítulo 
(DCi) (medidos por meio de régua); o número de pétalas (NP) (feito manualmente) e a abertura total de botão (ATB). O diâmetro externo e o interno do capítulo foram mensurados durante o estádio R5, ou seja, no período em que a inflorescência está completamente aberta.

Os dados foram submetidos à análise de variância pelo Teste F e nos casos de significância realizou-se análise de regressão polinomial linear e quadrática utilizando-se do software estatístico Sisvar-ESAL (Ferreira, 2003).

\section{Resultados E Discussão}

As doses de silício afetaram significativamente apenas o diâmetro de capítulo externo (DCe) e a abertura total de botão (dias). Com exceção de DC, FSI, DCe e NB, houve diferença significativa pelas cultivares nas variáveis avaliadas embora não tenha ocorrido efeito significativo da interação entre os tratamentos ( $\mathrm{S} \times \mathrm{C}$ ) (Tabela 1).

A aplicação de doses silício não influenciou a altura da planta nem o diâmetro caulinar (Tabela 1) corroborando com Carvalho et al. (2009) e discordando de Kamenidou et al. (2008) ao verificarem que a aplicação do silício aumentou a altura de plantas e o diâmetro caulinar do girassol ornamental "Ring of Fire". A falta de efeito do silicato de cálcio e magnésio em relação às características de crescimento do girassol pode estar relacionada ao tempo curto para maior solubilização e liberação de cálcio e magnésio e até mesmo de silício, para a planta, no período de avaliação.

Observou-se superioridade em altura das plantas de girassol cultivar Sol Vermelho em relação à Jardim Amarelo Alto (Figura 1) independentemente da dose de silício fornecida ao solo sendo esta superioridade de $124,70 \%$. As alturas médias de planta das cultivares Sol Vermelho e Jardim Amarelo Alto foram de 85 e $35,3 \mathrm{~cm}$ e corresponderam às alturas das cultivares Sunbrigth e Dobrado Amarela Anã, respectivamente, encontradas por Neves et al. (2005) e Silva et al. (2009).

O diâmetro caulinar (Tabela 1) das plantas de girassol cultivar Sol Vermelho $(6,96 \mathrm{~mm})$ não foi superior em relação à cultivar Jardim Amarelo Alto $(6,43 \mathrm{~mm})$; no entanto, esses valores foram semelhantes a $8,0 \mathrm{~mm}$ encontrados na cultivar Sunbright, por Neves et al. (2005) que avaliaram dois substratos no cultivo com solução nutritiva.

Aárea foliar é um índice importante em estudos de nutrição e crescimento vegetal visto que determina o acúmulo de matéria

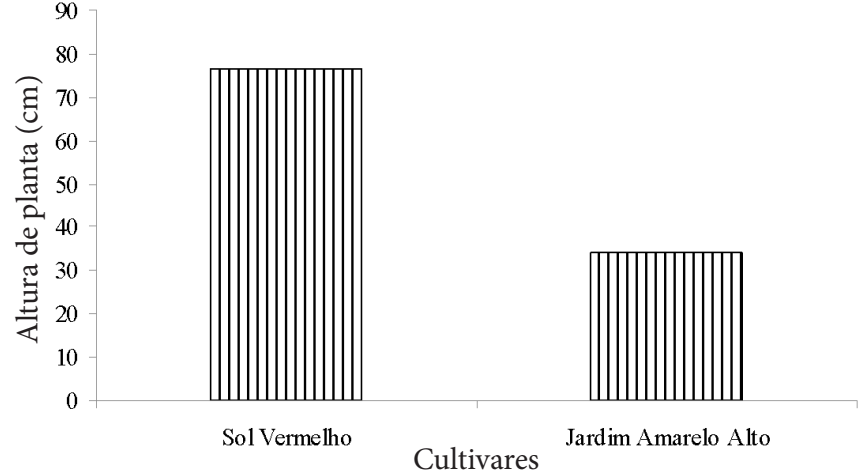

Figura 1. Altura de planta das cultivares de girassol Sol Vermelho e Jardim Amarelo Alto aos 60 DAS

seca, o metabolismo vegetal, a capacidade fotossintética potencial, o rendimento e a qualidade da colheita (Jorge \& Gonzalez, 1997). De acordo com os resultados do teste F (Tabela 1) a área foliar do girassol variou aos 60 DAS obtendose valores médios de 882,38 e $322,63 \mathrm{~cm}^{2}$ nas cultivares Sol Vermelho e Jardim Amarelo Alto, respectivamente (Figura 2). No entanto, com as doses 8 e $6 \mathrm{~g} \mathrm{vaso}^{-1}$ de silício, essas cultivares apresentaram maiores valores de área foliar, ou seja, $1259,83 \mathrm{~cm}^{2}$ e $402,64 \mathrm{~cm}^{2}$, respectivamente. A área foliar da cultivar Sol Vermelho foi semelhante à da cultivar Sunbrigth com $1300 \mathrm{~cm}^{2}$ obtida por Neves et al. (2005).

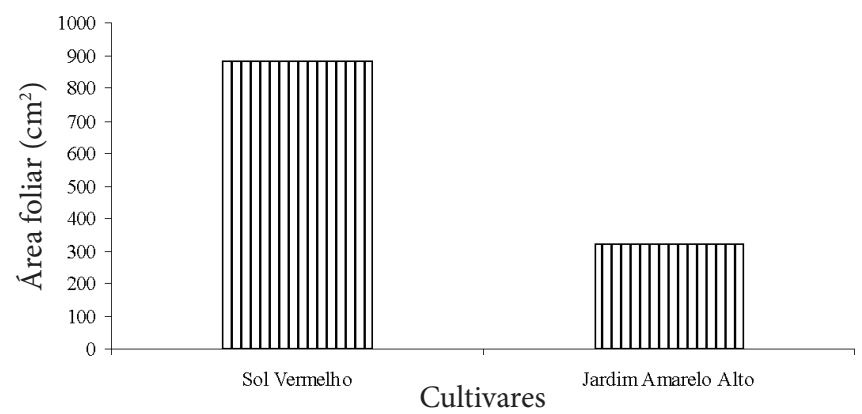

Figura 2. Área foliar de duas cultivares de girassol Sol Vermelho e Jardim Amarelo Alto aos 60 DAS

Os valores de área foliar são relacionados diretamente com o número de folhas, ou seja, quanto maior o número de folhas maior também será a área foliar. Assim, o número de folhas apresentou comportamento semelhante ao da área foliar, isto é, a cultivar Sol Vermelho foi significativamente superior

Tabela 1. Resumo do teste $F$ para altura de planta (AP), diâmetro caulinar (DC), número de folhas (NF), área foliar $(\mathrm{AF})$, fitomassa seca da parte aérea (FSPA), fitomassa seca de folhas (FSF), fitomassa seca de inflorescência (FSI), diâmetro de capítulo externo (DCe) e interno (DCi), número de pétalas por capítulo (NP) e abertura total de botão (dias) por planta de girassol (ATB) sob diferentes doses de silício (S) e cultivares (C) de girassol

\begin{tabular}{|c|c|c|c|c|c|c|c|c|c|c|c|}
\hline \multirow{2}{*}{ Fonte de variação } & \multicolumn{11}{|c|}{ Teste F } \\
\hline & $A P^{1}$ & DC & NF & $\mathrm{AF}$ & FSPA $^{1}$ & $\mathrm{FSF}^{1}$ & $\mathrm{FSI}^{1}$ & DCe & $\mathrm{DCi}^{1}$ & NP1 & ATB (dias) \\
\hline Doses de silício (S) & ns & ns & ns & ns & ns & ns & ns & * & ns & ns & * \\
\hline Reg. Linear & ns & ns & ns & ns & ns & ns & ns & ns & ns & ns & * \\
\hline Reg. Cúbica & ns & ns & ns & ns & ns & ns & ns & ns & ns & ns & ns \\
\hline Cultivares (C) & $\star \star$ & ns & * & ** & $\star *$ & $\star \star$ & ns & ns & $\star \star$ & ** & ns \\
\hline $\begin{array}{l}\mathrm{S} \times \mathrm{C} \\
\mathrm{CV} \%\end{array}$ & $\begin{array}{c}\text { ns } \\
13,43\end{array}$ & $\begin{array}{c}\text { ns } \\
10,83\end{array}$ & $\begin{array}{c}\text { ns } \\
17,27\end{array}$ & $\begin{array}{c}\text { ns } \\
57,85\end{array}$ & $\begin{array}{c}\text { ns } \\
16,41\end{array}$ & $\begin{array}{c}\text { ns } \\
14,33\end{array}$ & $\begin{array}{c}\text { ns } \\
15,11\end{array}$ & $\begin{array}{c}\text { ns } \\
14,30\end{array}$ & $\begin{array}{c}\text { ns } \\
7,29\end{array}$ & $\begin{array}{c}\text { ns } \\
8,25\end{array}$ & $\begin{array}{c}\text { ns } \\
5,19\end{array}$ \\
\hline
\end{tabular}

$\mathrm{ns}, * *$ * respectivamente não significativo, significativo a $\mathrm{p}<0,01 \mathrm{e}<0,05 ;{ }^{1}$ análise estatística realizada após transformação de dados em $\sqrt{ } \mathrm{X}$ (AP, FSPA, FSF, FSI, Dci, NP e ATB) 
à Jardim Amarelo Alto apresentando, em média, 17 e 14 folhas, respectivamente. Esses valores foram semelhantes aos encontrados por Neves et al. (2005) com a cultivar Sunbrigth.

As doses de silício aplicadas no substrato não aumentaram significativamente as produções de fitomassa seca de folhas (FSF), de parte aérea (FSPA) nem de inflorescência (FSI) (Tabela 1) corroborando com Carvalho et al. (2009). A fitomassa seca da parte aérea do girassol cultivado com e sem silício foi semelhante à obtida por Carvalho et al. (2009). De acordo com Lima et al. (2011) a aplicação foliar de silicato de sódio nas culturas do feijoeiro e do milho e a aplicação no solo no feijoeiro também não proporcionaram alterações significativas na matéria seca das folhas e dos caules. Entretanto, Gunes et al. (2008) e Zanão Júnior et al. (2009) verificaram aumento da produção de matéria seca da parte aérea com o fornecimento de silício em girassol e em arroz, respectivamente.

A área foliar, o número das folhas e, consequentemente, a fitomassa seca das folhas da cultivar Jardim Amarelo Alto, foram menores do que os da cultivar Sol Vermelho devido, provavelmente, ao fato do silício estar associado à maior retenção foliar da cultivar Jardim Amarelo Alto, em virtude da manutenção da fotossíntese e distribuição de clorofila (Agarie et al., 1998).

Em relação às doses de silicato, a resposta da FSI teve comportamento quadrático estimando-se o valor máximo de 4,43 g por planta com 4,1 g por vaso. Este valor de FSI foi maior do que 2,16 g por planta observado por Silva et al. (2009) avaliando plantas de girassol ornamental, cultivar Dobrada Amarela Anã, irrigadas com água com $0,5 \mathrm{dS} \mathrm{m}^{-1}$, durante 70 dias após o semeio.

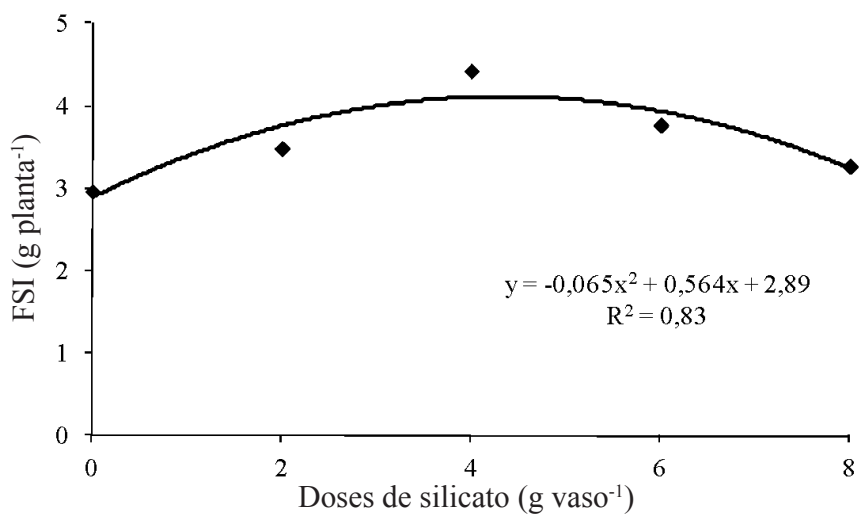

Figura 3. Variação da fitomassa seca de inflorescência (FSI) em razão das doses de silicato de cálcio

A ausência de resposta de diversas variáveis das cultivares do girassol ao silicato de cálcio, talvez se deva às baixas doses utilizadas ou, segundo Zanão Júnior et al. (2010), até mesmo doses muito elevadas pois, conforme Birchall (1995) podem haver polimerização e produção de partículas coloidais de sílica hidratada $\left(\mathrm{SiO}_{2} \cdot \mathrm{H}_{2} \mathrm{O}\right)$. Outros fatores relacionados a essa ausência de resposta, são a utilização de fontes de Si com baixa solubilidade e o teor de Si no solo ou substrato se encontrar acima do nível crítico (Carvalho et al., 2009).

Em relação ao comportamento das cultivares observouse superioridade em FSPA e FSF das plantas da cultivar girassol Sol Vermelho em relação à da Jardim Amarelo Alto independentemente da dose de silício (silicato de cálcio) fornecida ao solo (Figura 4). Silva et al. (2009) concluíram, avaliando o efeito da condutividade elétrica da solução nutritiva, que os dados médios observados da FSPAérea (8,37 g por planta) e da FSFolha (3,09 g por planta) correspondentes à cultivar Dobrada Amarela Anã, foram semelhantes aos dos resultados referentes à cultivar Jardim Amarelo Alto (Figura 4).

A

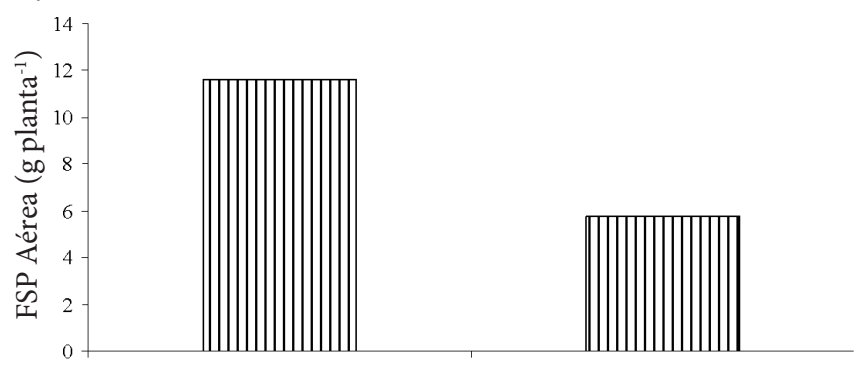

B.

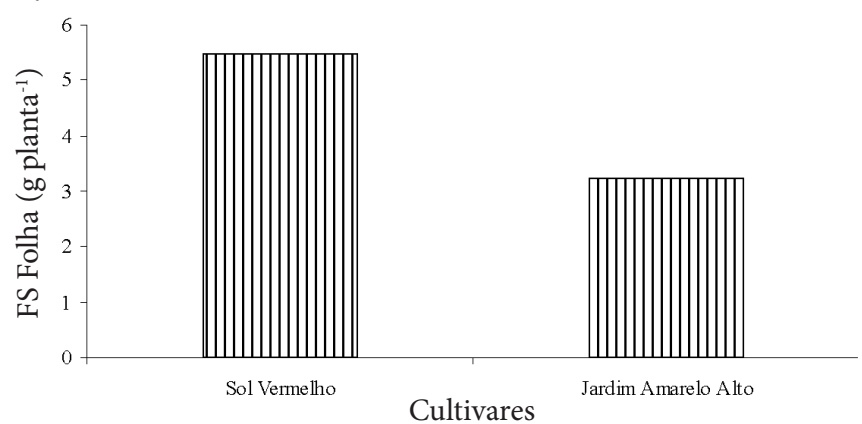

Figura 4. Fitomassa seca da parte aérea (FSP Aérea) e fitomassa seca das folhas (FS Folha) das cultivares de girassol Sol Vermelho e Jardim Amarelo Alto aos 60 DAS

De acordo com os resultados do teste $\mathrm{F}$ (Tabela 1) o diâmetro externo do capítulo (DCe) variou $(\mathrm{p}<0,01)$ com as doses de silício, mesmo que não tenha ocorrido variação entre as cultivares. Conforme os resultados, os maiores valores do $\mathrm{DCe}$ foram correspondentes à dose $4 \mathrm{~g}$ por vaso de silício com 15,33 cm e 14,3 cm das cultivares Sol Vermelho e Jardim Amarelo Alto, respectivamente. Esses resultados corroboraram com Neves et al. (2005) e com Carvalho et al. (2009) que obtiveram aumento do diâmetro médio das inflorescências com o aumento das doses de silício e segundo esses autores, a utilização do silício na fertilização do girassol ornamental cultivada em vaso pode ser uma alternativa viável visto que aumenta o diâmetro da inflorescência o qual, juntamente com a altura de plantas, é a característica mais importante que influencia a comercialização desta planta (Sloan \& Harkness, 2006). A inflorescência das duas cultivares foi viável comercialmente por estar de acordo com a Sakata Seed Corporation (2003) que exige valores de diâmetro de inflorescência entre 10,0 e 15,0 cm de bráctea a bráctea.

Segundo os dados da Tabela 1, as doses de silicato não influenciaram significativamente o diâmetro interno do capitulo (DCi); no entanto, houve diferença significativa entre as cultivares $(\mathrm{p}<0,01)$ (Figura 5).

De acordo com os dados referentes aos diâmetros externo e interno do capítulo, observou-se que a cultivar Sol Vermelho 


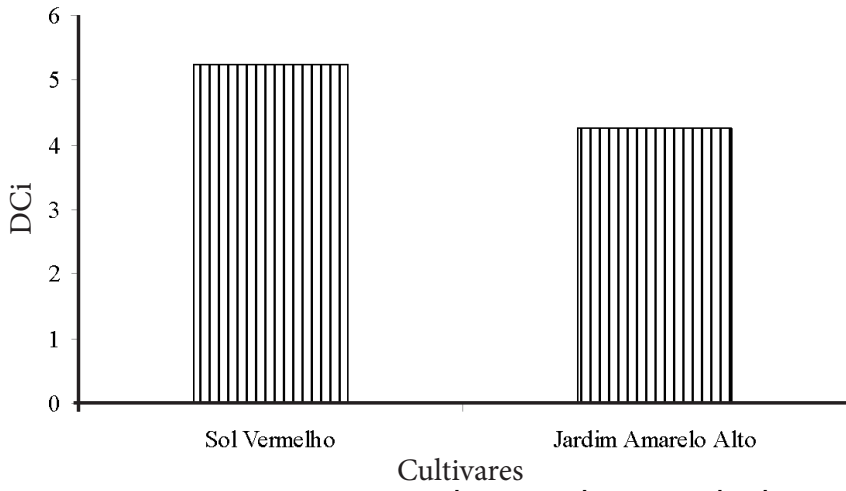

Figura 5. Diâmetro interno do capítulo (DCi) de duas cultivares de girassol Sol Vermelho e Jardim Amarelo Alto

apresenta capítulo maior que o da Jardim Amarelo Alto, haja vista que os valores médios dos diâmetros externos foram 13,14 e $11,82 \mathrm{~cm}$ e dos diâmetros internos foram 5,25 e 4,25 $\mathrm{cm}$, respectivamente, corroborando com Silva et al. (2009) em relação ao diâmetro interno. Desta forma, o maior diâmetro do capítulo produziu maior número de pétalas, ou seja, as cultivares Sol Vermelho e Jardim Amarelo Alto apresentaram, respectivamente, de 25 e 19 pétalas (Figura 6), as quais foram significativamente influenciadas pelas doses de silício $(p<0,01)$ (Tabela 1). Isto indica que o girassol é uma planta acumuladora de silício (Ma et al., 2001).

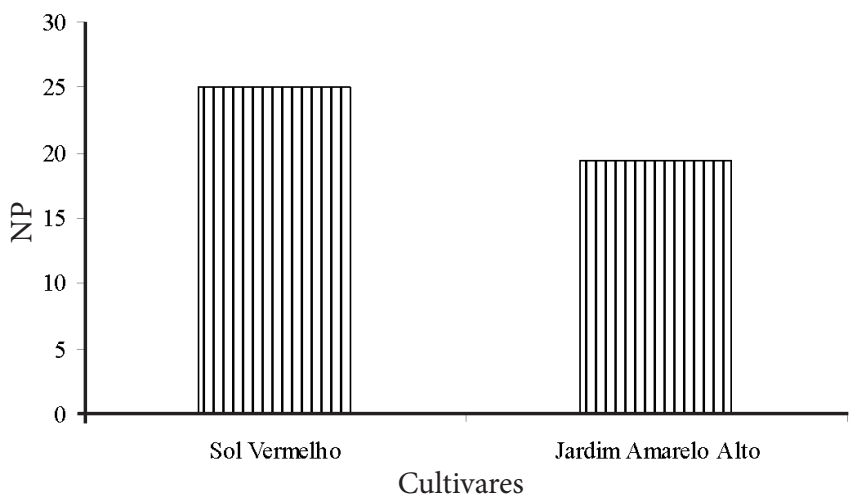

Figura 6. Número de pétalas de duas cultivares de girassol Sol Vermelho e Jardim Amarelo Alto

As doses de silicato exerceram efeito significativo $(\mathrm{p}<$ $0,05)$ sobre a abertura total de botões (ATB) - (dias) (Tabela 1). Conforme equações de regressão referentes ao ATB (dias), o modelo ao qual os dados se ajustaram melhor foi o linear, indicando um acréscimo de $11,1 \%$ quando foram comparadas as doses zero a $8 \mathrm{~kg}$ por vaso de silicato (Figura 7).

\section{Conclusões}

1. A altura de plantas, diâmetro caulinar, número de folhas, área foliar, fitomassa seca da parte aérea, fitomassa seca das folhas, fitomassa seca de inflorescência, diâmetro do capítulo interno e o número de pétalas por capítulo, não diferem estatisticamente com as doses de silício.

2. O silício aumenta o diâmetro do capítulo externo e a abertura total de botões (dias) por planta de girassol.

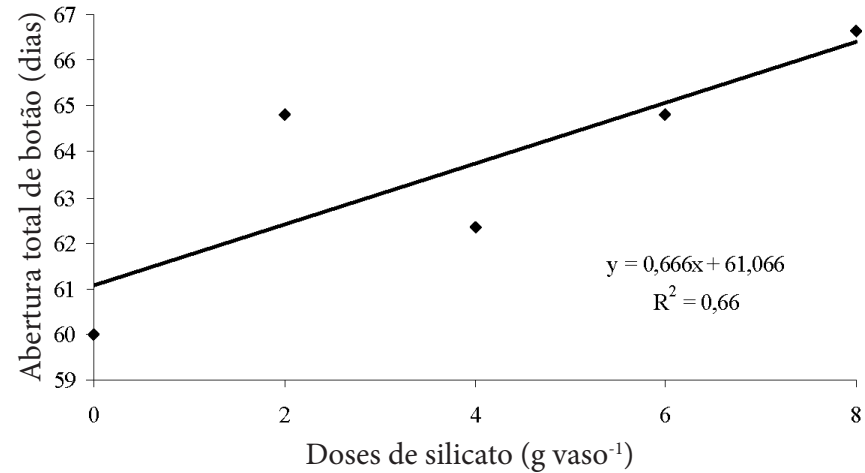

Figura 7. Abertura total de botões (dias) em razão das doses de silício

4. A cultivar Sol Vermelho apresenta maior altura de plantas, número de folhas, área foliar; fitomassa seca da parte aérea, fitomassa seca das folhas, diâmetro do capítulo interno e número de pétalas por capítulo, que a cultivar Jardim Amarelo Alto.

\section{Agradecimentos}

Os autores agradecem à ISLA SEMENTES LTDA, pelo fornecimento do material propagativo (sementes) e a Hascos Minerais, pela doação do agrossilício utilizado no experimento.

\section{Literatura Citada}

Agarie, S.; Agata, W.; Kaufman, P. B. Involvement of silicon in the senescence of rice leaves. Plant Production Science, v.1, p.104-105, 1998.

Al-Aghabary, K.; Zhu, Z.; Shi, Q. Influence of silicon supply on chlorophyll content, chlorophyll fluorescence, and antioxidative enzyme activities in tomato plants under salt stress. Journal of Plant Nutrition, v.12, p.2101-2115, 2004.

Amaral, D. R; Resende, M. L. V; Ribeiro Júnior, P. M; Borel, J. C; Mac Leod, R. E. O; Pádua, M. A. Silicato de potássio na proteção do cafeeiro contra Cercospora coffeicola. Tropical Plant Pathology, v.33, p.425-431, 2008.

Birchall, J. D. The essentiality of silicon in biology. Chemical Society Reviews, v.24, p.351-357, 1995.

Carvalho, M. P.; Zanão Junior, L. A.; Grossi, J. A. S.; Barbosa, J. G. Silício melhora produção e qualidade do girassol ornamental em vaso. Ciência Rural, v.39, p.2394-2399, 2009.

Coelho, M. A.; Soncin, N. B. Geografia do Brasil. São Paulo: Moderna, 1982. 368p.

Demattê, J. L. I.; Pagiaro, C. M.; Beltrame, J. A.; Ribeiro, S. S. Uso de silicatos em cana-de-açúcar. Informações Agronômicas, n.133, p.7-12, 2011.

EMBRAPA - Empresa Brasileira de Pesquisa Agropecuária. Manual de métodos de análises de solo. 2.ed. Rio de Janeiro, Ministério da Agricultura e do Abastecimento, 1997.212p.

EMBRAPA - Empresa Brasileira de Pesquisa Agropecuária. Centro Nacional de Pesquisa de Soja. 2003.Girassol:sistemas de produção. http:// www. cnpso. embrapa. br/index.php? op_page $=54 \&$ cod _pai $=38.03$ Out. 2011.

Ferreira, D. F. V. Sisvar 4.6. Sistema de análises estatísticas. Lavras: UFLA, 2003. 32p. 
Gunes, A.; Pilbeam, D. J.; Inal, A.; Coban, S. Influence of silicon on sunflower cultivars under drought stress, I: Growth, antioxidant mechanisms, and lipid peroxidation. Communications in Soil Science and Plant Analysis, v.39, p.1885-1903, 2008.

Higaki, T.; Imamura, J. S.; Paull, R. E. N, P and K rates and leaf tissue standards for optimum Anthurium andreanum flower production. HortScience, v.27, p.909-912, 1992.

Jorge, Y.; Gonzalez, F. Estimación del área foliar en los cultivos de ají y tomate. Agrotecnia de Cuba, v.27, p.123126, 1997.

Kamenidou, S.; Cavins, T. J.; Marek, S. Silicon supplements affect horticultural traits of greenhouse-produced ornamental sunflowers. HortScience, v.43, p.236-239, 2008.

Lima, M. A.; Castro, V. F.; Vidal, J. B.; Enéas-Filho, J. Aplicação de silício em milho e feijão-de-corda sob estresse salino. Revista Ciência Agronômica, v.42, p.398403, 2011.

Ma, J. F.; Miyake, Y.; Takahashi, E. Silicon as a beneficial element for crop plants. In: Datnoff, L. E.; Snyder, G. H.; Korndörfer, G. H (ed.). Silicon in Agriculture: studies in plant science. Amsterdam: Elsevier, v.8, p.17-39, 2001.

Maldaner, I. C.; Heldwein, A. B.; Loose, L. H.; Lucas, D. D. P.; Guse, F. I.; Bortoluzzi; M. P. Modelos de determinação não-destrutiva da área foliar em girassol. Ciência Rural, v.39, p.1356-1361, 2009.

Neves, M. B.; Buzetti, S.; Castilho, R. M. M.; Boaro, C. S. F. Desenvolvimento de plantas de girassol ornamental (Helianthus annuus L.) em vasos, em dois substratos com solução nutritiva e em solo. Científica, v.33, p.127-133, 2005.
Pinto, S. I. C.; Ramos, S. J.; Araujo, J. L.; Faquin, V.; Novais, C. B.; Silva, K.; Furtini Neto, A. E. Silício como amenizador da fitotoxicidade de zinco em plantas jovens de Eucalyptus urophylla cultivadas em solução nutritiva. Revista Árvore, v.33, p.1005-1014, 2009.

Rodrigues, F. A,; Oliveira, L. A.; Korndörfer, A. P.; Korndörfer, G. H. Silício: um elemento benéfico e importante para as plantas. Informações Agronômicas, n.134, p.14-20, 2011.

Sakata Seed Corporation. Sakata's reliable seeds: Flower seed catalogue 2001-2003. Bragança Paulista: Sakata Sementes Agroflora, 2003. 99p.

Schoellhorn, R.; Emino, E.; Alvarez, E.Specialty cut flower production guides for Florida: sunflower. Gainesville: University of Florida, IFAS Extension, 2003. 3p.

Silva T. G. F.; Zolnier, S.; Grossi, J. A. S.; Barbosa, J. G.; Moura C. R. W.; Muniz, M. A. Crescimento do girassol ornamental cultivado em ambiente protegido sob diferentes níveis de condutividade elétrica de fertirrigação. Revista Ceres, v.56, p.602-610, 2009.

Sloan, R. C.; Harkness, S. S. Field evaluation of pollenfree sunflower cultivars for cut flower production. HortTechnology, v.16, p.324-327, 2006.

Zanão Júnior, L. A.; Fontes, R. L. F.; Ávila, V. T. Teores foliares de nutrientes e de silício em plantas de arroz infectadas por Bipolaris oryzae. Scientia Agrária, v.11, p.87-90, 2010.

Zanão Júnior, L. A. ; Rodrigues, F. A.; Fontes, R. L. F.; Neves, J. C. L.; Korndorfer, G. H. Rice resistance to brow spot mediated by silicon and its interaction with manganese. Journal of Phytopathology, v.157, p.73-78, 2009.

Zobiole, L. H. S.; Castro, C.; Oliveira, F. A.; Oliveira Júnior, A. Marcha de absorção de macronutrientes na cultura do girassol. Revista Brasileira de Ciência do Solo, v.34, p.425433, 2010. 